\title{
Antioxidant effect of Phyllanthus emblica extract prevents contrast-induced acute kidney injury
}

\author{
Adis Tasanarong ${ }^{1 *}$, Supranee Kongkham ${ }^{2}$ and Arunporn Itharat $^{3}$
}

\begin{abstract}
Background: Contrast-induced acute kidney injury (CI-AKI) occurs after the administration of intravenous iodinated contrast agents. Oxidative stress has been proposed as one of the most important mechanisms in the pathogenesis of Cl-AKI. The objective of this study was to investigate the antioxidant effect of the extract from Phyllanthus emblica (PE) in preventing $\mathrm{Cl}-\mathrm{AKI}$.

Methods: Male Sprague Dawley rats were subjected into eight groups, were given water (control) or PE extract (125 or 250 or $500 \mathrm{mg} / \mathrm{kg} /$ day) for 5 days before the induction of Cl-AKI. Renal function and oxidative stress markers; malondialdehyde (MDA), total antioxidant capacity (TAC), superoxide dismutase (SOD) and catalase (CAT) activity were determined in plasma and renal tissue. Kidney sections were performed for histopathological examination.

Results: In the contrast media (CM) group, increases in blood urea nitrogen and serum creatinine were demonstrated which correlated with severity of tubular necrosis, peritubular capillary congestion and interstitial edema. Moreover, an increase in MDA and a decrease in TAC SOD and CAT activity in CM group were significantly changed when compared with the control $(P<0.05)$. In contrast, $C l$-AKl-induced rats administrated with PE extract 250 and $500 \mathrm{mg} / \mathrm{kg} /$ day significantly preserved renal function and attenuated the severity of pathological damage $(P<0.05)$ as well as significantly lower MDA and higher TAC, SOD and CAT than the CM group $(P<0.05)$.
\end{abstract}

Conclusions: This study demonstrated the protective role of PE extract against Cl-AKI.

Keywords: Phyllanthus emblica, Gallic acid, Antioxidant, Contrast-induced acute kidney injury

\section{Background}

Contrast-induced acute kidney injury (CI-AKI) is the common iatrogenic cause of acute kidney injury (AKI) following the use of intravenous contrast media (CM) $[1,2]$. The incidence of CI-AKI is 1 to $2 \%$ in low risk patients with normal renal function but increases up to $25 \%$ in high risk patients with chronic renal impairment or diabetes mellitus [2]. CI-AKI particularly in chronic kidney disease patients increases the hospitalizations and long term morbidity and mortality [3]. The pathogenesis of CI-AKI is due to the ability of contrast agents could induce renal vasoconstriction followed by hypoxic condition in the kidney which promotes further ischemic renal injury by the increase of oxygen free-radicals through oxidative stress [4]. Renal injury occurs when the hypoxic

\footnotetext{
* Correspondence: adis_tasanarong@hotmail.com

'Nephrology Unit, Department of Medicine, Faculty of Medicine, Thammasat University (Rangsit Campus), Klong Nung, Klong Luang, Pathumtani 12121, Thailand

Full list of author information is available at the end of the article
}

tissue generates reactive oxygen species (ROS) exceed than antioxidant reservation in the renal tissue [5]. Many strategies to prevent CI-AKI have been tested in many experimental studies and clinical trials. Hydration with isotonic saline has been recommended to prevent CI-AKI [6]. Additional antioxidants agents such as $\mathrm{N}$-acetylcysteine, ascorbic acid and others demonstrated the conflicting results to CI-AKI prevention [7-9].

Phyllanthus emblica (PE) also known as Amla or Indian Gooseberry or Ma-Khaam-Pom in Thai is a natural fruit that contains high concentrations of acorbic acid $[10,11]$, gallic acid [12], and mixture of phenolic compounds [13]. Active extracts of PE have been shown to posses anticancer $[14,15]$, radioprotection [16], anti-inflammatory [17] and antioxidant $[18,19]$ properties in several models of organ injury.

PE has never been used to assess its antioxidant effect in CI-AKI. The present study was designed to investigate the benefit of the PE extract in preventing CI-AKI and 
to discover the active substance in PE extract on CI-AKI prevention.

\section{Methods Sample}

Phyllantus embelica fruits collected from Ampor Marim, Chiengmai Province Thailand on December 2011, were dried by oven at $50^{\circ} \mathrm{C}$. Dry plant material $(10 \mathrm{~kg})$ was grinded and boiled in water for $30 \mathrm{~min}$, filtered and evaporated by evaporator. The extract was dried by freeze dry as water extract of PE (PEW). The percentage of yield obtained as $40.81 \%$. The samples have been preserved in the refrigerator $\left(-20^{\circ} \mathrm{C}\right)$. Authentication of plant materials was identified by comparing against the specimens deposited at the herbarium of Southern Center of Thai Medicinal Plants, Faculty of Pharmaceutical Science, Prince of Songkla University, Songkla, Thailand, where herbarium vouchers have been kept (Herbarium no.SKP 071160501).

\section{Chemicals}

Ascorbic acid, gallic acid and quercetin, thiobarbituric acid (TBA), 2, 2'-azinobis (3-ethylbenzothia-zoline-6sulfonic acid) diammonium salt (ABTS), Trolox and all other chemical reagents were purchased from SigmaAldrich (Singapore). The low-osmolar, nonionic contrastmedia agent (Iopromide) was obtained from Schering AG (Germany).

\section{Preparing standard ascorbic acid, Gallic acid and Quercetin}

Ascorbic acid, Gallic acid and Quercetin were prepared as concentration as $1 \mathrm{mg} / \mathrm{ml}$. Ascorbic acid and quercetin were prepared for 5 concentration per 1 millitre such as $6.25,12.5,25,50$ and $100 \mu \mathrm{g} / \mathrm{ml}$. Gallic acid were also prepared for 5 concentration per 1 millitre such as 25,50 , 100,200 and $400 \mu \mathrm{g} / \mathrm{ml}$. Injection for these standard compounds for triplicate $(\mathrm{N}=3)$.

\section{Preparing for sample}

Preparing PEW as concentration $10 \mathrm{mg} / \mathrm{ml}$ was filtrated by syringe filter nylon, pore size $0.45 \mu \mathrm{m}$ and injected in High Performance Liquid Chromatography (HPLC) instrument by triplicate $(\mathrm{N}=3)$.

\section{HPLC analysis}

The HPLC instrument is belong to Agilent Co. LTD (LC1200) (USA), Column: Phenomenex ${ }^{\oplus}$ Luna $5 \mu$ C18(2) 100A size $250 \times 4.60 \mathrm{~mm} 5$ micron, Mobile phase: $0.1 \%$ Acetic acid in water (A): Methanol (B), gradient elution; $0-15 \mathrm{~min}$ as $5 \% \mathrm{~B}, 15-40 \mathrm{~min}$ as $80 \% \mathrm{~B}, 40-42 \mathrm{~min}$ as $5 \%$ $\mathrm{B}$ and $42-45$ as $5 \% \mathrm{~B}$, Flow rate: $0.9 \mathrm{ml} / \mathrm{min}$, Detection: UV $280 \mathrm{~nm}$, Injection volume: $20 \mu \mathrm{l}$.

\section{Animals}

Male Sprague Dawley rats from the national animal center (Mahidol University) were used. The experiments were approved by the animal ethics committee of faculty of medicine, Thammasat University. All rats were housed in a temperature controlled room $\left(24^{\circ} \mathrm{C} \pm 1^{\circ} \mathrm{C}\right)$ and were given standard food pellets and tap water until they weighed 250-300 g, prior to the induction of CI-AKI. Rats were divided into eight groups of 6 rats to each group as follows: group 1, rats given sterile water (control); group 2 , rats given sterile water followed by CI-AKI induction (CM); group 3, rats given PE extract $125 \mathrm{mg} / \mathrm{kg} /$ day (PE $125 \mathrm{mg}$ ); group 4, rats given PE extract $125 \mathrm{mg} / \mathrm{kg} /$ day followed by CM (PE $125 \mathrm{mg}+\mathrm{CM}$ ), rats in both group 5 and group 6 given PE extract $250 \mathrm{mg} / \mathrm{kg} /$ day (PE $250 \mathrm{mg}$ ) but in group 6 was followed by CM (PE $250 \mathrm{mg}+\mathrm{CM}$ ), group 7 and group 8 were given PE extract $500 \mathrm{mg} / \mathrm{kg} /$ day (PE $500 \mathrm{mg}$ ) but group 8 was followed by CM (PE $500 \mathrm{mg}+\mathrm{CM})$. PE or sterile water were orally administrated for 5 days, and then rats in Group 2, Group 4, Group 6 and Group 8 were established with model of CIAKI on the next day. The day after CI-AKI induction, all experimental animals were euthanized by inhalation of ether anesthesia.

\section{Introduction of $\mathrm{Cl}-\mathrm{AKI}$ in Rats}

CI-AKI rats were subjected to CI-AKI protocol as described [20-22] briefly; pentobarbital sodium $(60 \mathrm{mg} / \mathrm{kg})$ anesthesia by intraperitoneal injection was followed by CI-AKI induction, which was performed with drug administration into tail vein. Drug administered consisted of indomethacin at a dose of $10 \mathrm{mg} / \mathrm{kg}$, followed at $15 \mathrm{~min}$ and $30 \mathrm{~min}$ later with $\mathrm{N}^{\mathrm{w}}$-nitro-L-Arginine methyl ester (L-NAME) at dose of $10 \mathrm{mg} / \mathrm{kg}$ and with lowosmolar, non-ionic contrast medium agent (Iopromide) at a dose of $1600 \mathrm{mg}$ iodine $/ \mathrm{kg}$. This quantity is the dose of contrast medium that is standard for clinical use and for other relevant experiments in rat models. As controls, rats were injected with equivalent volume of saline at each time.

\section{Histopathologic examination of renal tissues}

Both kidneys were excised immediately and cut into four equatorial sections; they were then washed twice with cold PBS. Two pieces of kidney were placed in $10 \%$ formaldehyde for histopathological examination. The other pieces were flash-frozen in liquid nitrogen, and stored at $-70^{\circ} \mathrm{C}$ until used for subsequent tissue analysis. Histological slides of the formalin-maintained samples were prepared and counterstained with hematoxylin, eosin (H\&E) and periodic acid schiff staining (PAS). These steps were then followed by semi-quantitative analysis the kidney section by a pathologist functioning in a blind manner [21,23,24]. Tubular necrosis and proteinaceous 
cast were graded according to a previous methodology as follows: 0 = no damage; 1 = mild (unicellular, patchy isolated damage); $2=$ moderate (damage $<25 \%$ ); $3=$ severe (damage between 25 and $50 \%)$ and $4=$ very severe $(>50 \%$ damage). The degree of the medullary congestion was defined as: $0=$ no congestion; $1=$ mild (vascular congestion with identification erythrocytes by $\times 400$ magnification); 2 = moderate (vascular congestion with identification of erythrocytes by $\times 200$ magnification); $3=$ severe (vascular congestion with identification of erythrocytes by $\times 100$ magnifications) and $4=$ very severe (vascular congestion with identification of erythrocytes by $\times 40$ magnifications). Interstitial edema was graded as follows: $0=$ no edema; 1 = mild (unicellular, patchy isolated edema); 2 = moderate $($ edema $<25 \%) ; 3=$ severe (edema between 25 and $50 \%)$ and $4=$ very severe $(>50 \%$ edema $)$.

\section{Biochemistry assay}

In order to measure the oxidative stress markers including the oxidation of lipids, the antioxidant enzyme, total antioxidant capacity (TAC) and the renal function test, the serum was separated from blood that had been obtained from the heart and was kept at $-20^{\circ} \mathrm{C}$ until used. Renal function was investigated in serum blood urea nitrogen (BUN), and serum creatinine levels were determined using an automatic analyzer. All measurements were performed using standard methods in a single, hospital-based laboratory [25]. Also, oxidative stress markers were measured in kidneys. Renal tissue samples were prepared from $0.1 \mathrm{~g}$ of frozen renal tissue which were homogenized in $1 \mathrm{ml}$ of PBS ( $\mathrm{pH} 7.2$ ), and centrifuged at $10,000 \mathrm{~g}$ for $10 \mathrm{~min}$ at $4^{\circ} \mathrm{C}$; supernatant was then taken and kept at $-80^{\circ} \mathrm{C}$ until used. Protein contents in tissue homogenates were estimated by Bradford method using bovine serum albumin as a standard.

Lipid peroxidation, in term of malondialdehyde (MDA) was measured using thiobarbituric acid reactive substances (TBARS) assay, a method modified from that of Wong et al. [26]. Briefly, $100 \mathrm{ml}$ of serum or renal tissue samples were subjected to $0.75 \mathrm{ml}$ of phosphoric acid solution $(0.44 \mathrm{M})$ and incubated at room temperature for $10 \mathrm{~min} ; 5 \mathrm{ml}$ of TBA solution was then added. The mixtures were heated at $100^{\circ} \mathrm{C}$ for $30 \mathrm{~min}$. The samples were centrifuged at $4000 \mathrm{~g}$ for $10 \mathrm{~min}$. The absorbance of the supernatant was read at $532 \mathrm{~nm}$. The concentration of MDA was calculated from $0-20 \mu \mathrm{M}$ of standard MDA using 1,1,3,3 tetraethoxypropane. The results of the serum or renal MDA were expressed as $\mu \mathrm{M}$ or $\mu \mathrm{M}$ per mg of protein, respectively.

Total antioxidant capacity (TAC) was determined by modified ABTS decolorization method as described by Re et al. [27] ABTS (7 $\mathrm{mM}$ in final concentration), with potassium per sulfate added $(2.45 \mathrm{mM}$ final concentration). The initial absorbance of induced ABTS radical cation solution was approximately 0.7-0.02 at 734 $\mathrm{nm}$. After addition of $10 \mathrm{ml}$ of sample or Trolox standard to $1 \mathrm{ml}$ of diluted ABTS, the absorbance was measured at $734 \mathrm{~nm}$ after initial mixing. The TAC value was estimated by the reduction of absorbance at $734 \mathrm{~nm}$ and calculated against the curve of Trolox $(0-1 \mu \mathrm{M})$. The values of TAC were expressed in equivalence of $\mu \mathrm{M}$ Trolox or Trolox/mg of protein, when measured in the serum or renal tissue samples, respectively.

Renal superoxide dismutase (SOD) activity was also determined using the SOD kit (Sigma), following the manufacturing protocol. The SOD activity was measured and expressed as units per mg protein.

Renal catalase (CAT) activity was measured according to the modified method of Aebi et al. [28]. This method measures the exponential disappearance of $\mathrm{H}_{2} \mathrm{O}_{2}(10 \mathrm{mM})$ at $240 \mathrm{~nm}$ for $2 \mathrm{~min}$ at room temperature. The CAT activity was expressed as units per milligram of protein (one unit of catalase is equal to $1 \mu \mathrm{mol}$ of $\mathrm{H}_{2} \mathrm{O}_{2}$ decomposition/min).

\section{Statistical analysis}

Results were present as the means \pm SE. Student's $t$-test (when two groups were considered) and one-way ANOVA were used to determine the significance of differences in multiple group comparisons using SPSS software. A $p$-value of less than 0.05 was considered to be as significance. The area under the curve (AUC) was calculated using the trapezoid rule. The correlation between two continuous variables was assessed using Person's correlation coefficient and the coefficient of determination.

\section{Results}

\section{HPLC analysis of PE}

The five concentrations of ascorbic acid, gallic acid and quercetin were calculated and plotted as correlation graphs of concentration and AUC. The standard correlation between the concentration and AUC of ascorbic acid, gallic acid and quercetin were excellent, $R^{2}=0.999$, 0.9998 and 0.9991 respectively. Figure $1 \mathrm{~A}$ and B showed the HPLC chromatograms of standard ascorbic acid, gallic acid, quercetin and PE at UV 254, 370 and $280 \mathrm{~nm}$. From HPLC analysis, the mean percentages of ascorbic acid, gallic acid and quercetin in PE extract by weight/weight were $0.00,6.09 \pm 0.38$ and $0.68 \pm 0.06$ respectively.

\section{Effect of PE extract on renal function parameters}

Both BUN and serum $\mathrm{Cr}$ in the $\mathrm{CM}$ group were significantly increased when compared with the control $(\mathrm{p}<0.05)$. While BUN was significantly decreased in the PE extract $125 \mathrm{mg}+\mathrm{CM}$ group, PE extract $250 \mathrm{mg}+$ $\mathrm{CM}$ group and PE extract $500 \mathrm{mg}+\mathrm{CM}$ group when compared with $\mathrm{CM}$ group $(\mathrm{P}<0.05)$; Figure 2 . In addition, serum $\mathrm{Cr}$ was significantly decreased in only two of the 


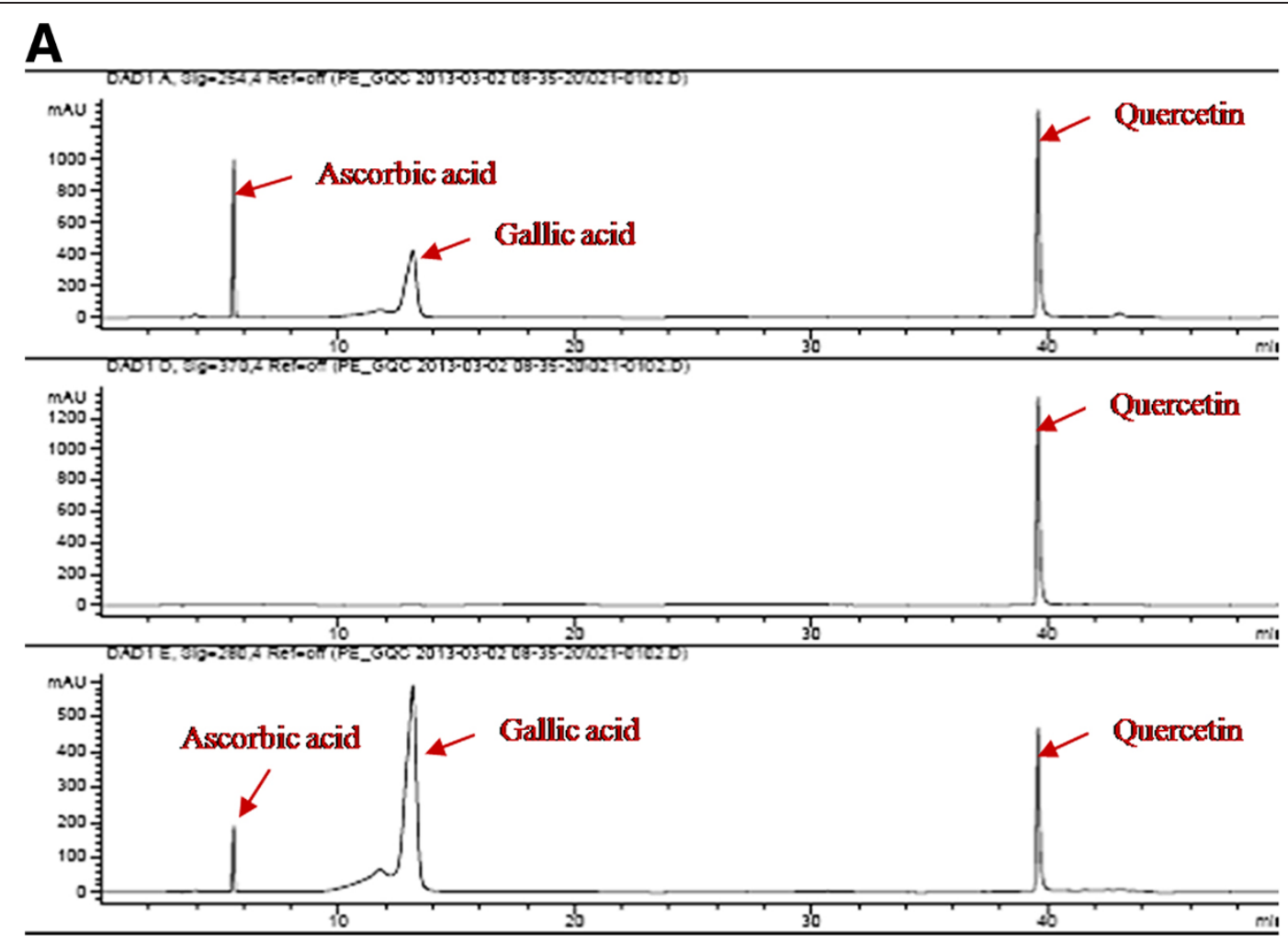

B

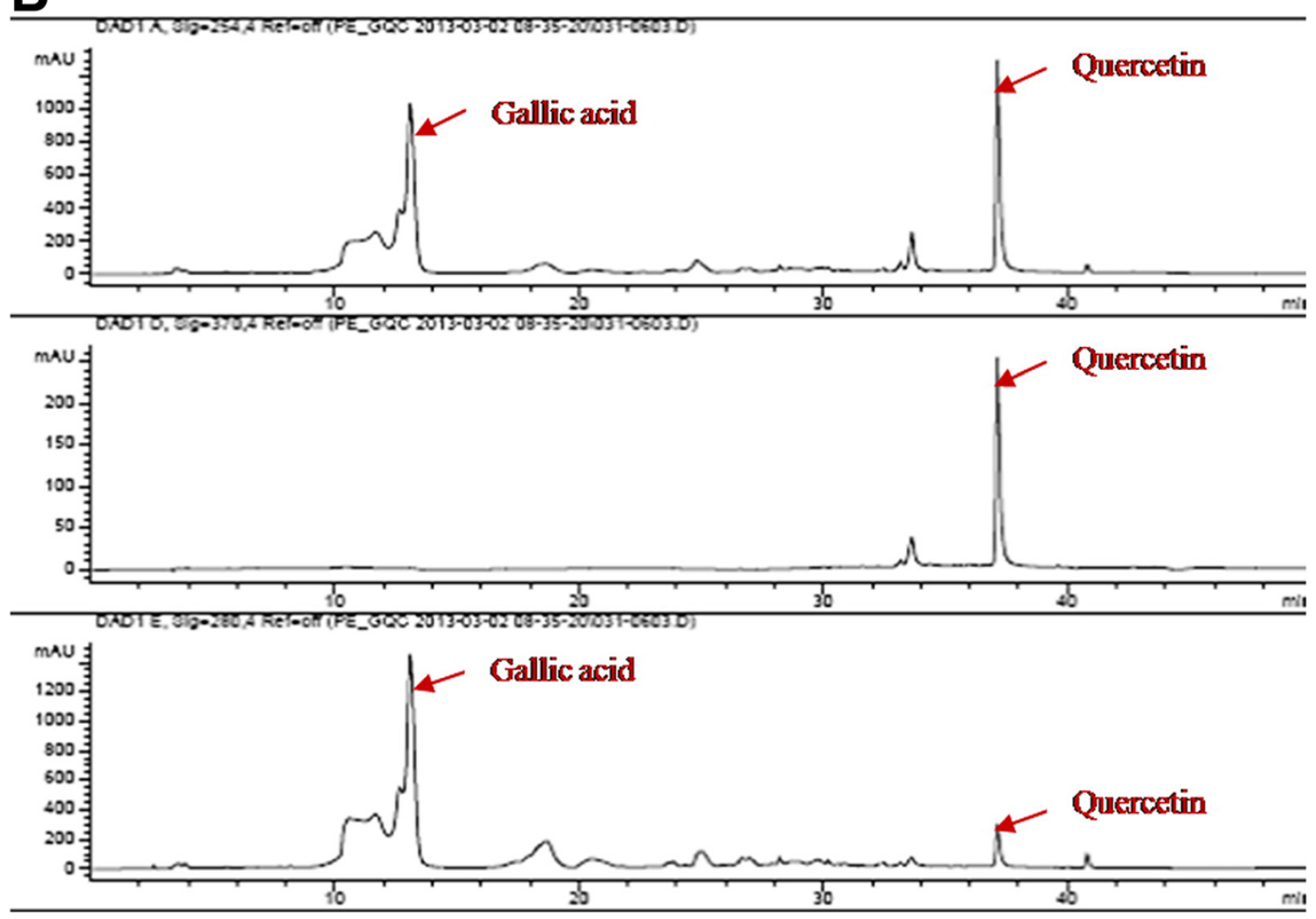

Figure 1 HPLC chromatogram of standard ascorbic acid, gallic acid and quercetin (1A) and PE extact (1B) at UV 254, 370 and $280 \mathrm{~nm}$. 


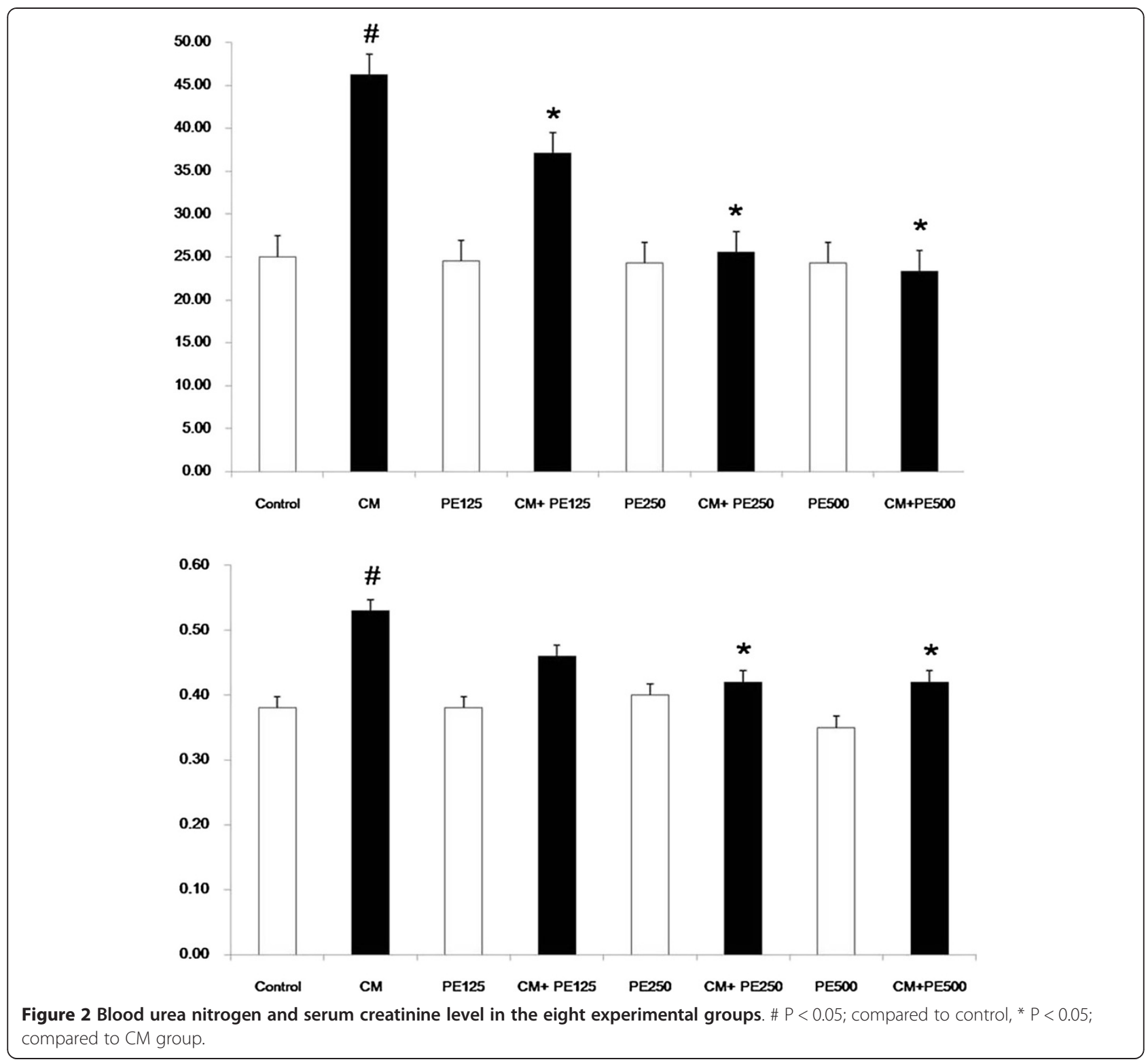

PE extract $250 \mathrm{mg}+\mathrm{CM}$ group and PE extract $500 \mathrm{mg}+$ $\mathrm{CM}$ group when compared with $\mathrm{CM}$ group $(\mathrm{P}<0.05)$; Figure 2.

\section{Effect of PE extract on attenuation of renal histopathology}

Histological evaluation of kidney sections in the CM group revealed the significantly severe damage consisting of tubular necrosis, proteinaceous cast formation, PTC congestion and interstitial edema in the outer stripe of the outer medulla (OSOM) and cortex when compared with the control $(\mathrm{P}<0.05)$; Table 1 and Figure 3. Pretreatment with PE extract $250 \mathrm{mg}$ and PE extract $500 \mathrm{mg}$ in rats with CI-AKI induction were significantly attenuated the development of these lesions when compared with the $\mathrm{CM}$ group $(\mathrm{P}<0.05)$; Table 1 and Figure 3.

\section{Effect of PE extract on attenuation of oxidative stress on CI-AKI}

The serum and renal MDA levels in the CM group were significantly increased when compared with the control $(\mathrm{P}<0.05)$, whereas the MDA levels were significantly lower in the $\mathrm{PE}$ extract $250 \mathrm{mg}+\mathrm{CM}$ group and $\mathrm{PE}$ extract $500 \mathrm{mg}+\mathrm{CM}$ when compared with $\mathrm{CM}$ group $(\mathrm{P}<0.05)$; Figures 4 and 5 . The serum and renal TAC levels in the $\mathrm{CM}$ group were significantly decreased when compared with the control $(\mathrm{P}<0.05)$, while the TAC levels in the PE extract $250 \mathrm{mg}+\mathrm{CM}$ group and PE extract $500 \mathrm{mg}+$ $\mathrm{CM}$ group were significantly higher than the CM group 
Table 1 Histopathological analysis of tubular necrosis, PTC congestion and interstitial edema in the five experimental groups

\begin{tabular}{|c|c|c|c|c|c|}
\hline & Control $(n=6)$ & $C M(n=6)$ & CM PE $125 \mathrm{mg}(\mathrm{n}=6)$ & CM PE $250 \mathrm{mg}(n=6)$ & CM PE $500 \mathrm{mg}(\mathrm{n}=6)$ \\
\hline Tubular necrosis and proteinaceous casts & $0.1 \pm 0.3$ & $2.1 \pm 0.5^{\#}$ & $1.6 \pm 0.5$ & $1.3 \pm 0.5^{*}$ & $0.7 \pm 0.5^{*}$ \\
\hline PTC congestion & $0.3 \pm 0.5$ & $2.3 \pm 0.5^{\#}$ & $2.1 \pm 0.5$ & $1.8 \pm 0.4^{*}$ & $0.8 \pm 0.4^{*}$ \\
\hline Interstitial edema and infiltration & $0.2 \pm 0.4$ & $2.4 \pm 0.5^{\#}$ & $2.1 \pm 0.5$ & $1.8 \pm 0.4^{*}$ & $0.8 \pm 0.4^{*}$ \\
\hline
\end{tabular}

The score of histopathological changes, such as scores of tubular necrosis and proteinaceous cast, PTC congestion, interstitial edema and infiltration, are presented as means $\pm \mathrm{SD}$.

$\# \mathrm{P}<0.05$; compared to control.

*P $<0.05$; compared to $C M$.

CM: contrast media; PTC: peritubular capillaries.

$(\mathrm{P}<0.05)$; Figures 4 and 5 . Moreover the renal SOD and CAT levels were significantly decreased in $\mathrm{CM}$ group when compared with the control $(\mathrm{P}<0.05)$; Figure 5 . The renal SOD and CAT levels in the PE extract $125 \mathrm{mg}+$ $\mathrm{CM}, \mathrm{PE}$ extract $250 \mathrm{mg}+\mathrm{CM}$ and PE extract $500 \mathrm{mg}+$ $\mathrm{CM}$ group were significantly higher than the $\mathrm{CM}$ group $(\mathrm{P}<0.05)$; Figure 5.

\section{Discussion}

To our knowledge, this is the first study to demonstrate the renoprotective effect of PE extract to prevent the development of renal dysfunction and pathological destruction as assessed by biochemical and markers of oxidative stress in a rat model of CI-AKI. Prophylaxis with PE extract at doses of 250 and $500 \mathrm{mg} / \mathrm{kg} /$ day markedly suppressed renal tubular injuries and improved antioxidant activity in CI-AKI rats.

The nephrotoxic effects of radiocontrast media have been reported in many experimental studies $[21,24,29]$ and we followed the same methodology as reported elsewhere $[20,21,30]$. The histopathological studies confirmed significant acute tubular necrosis, vacuolization, loss of brush borders, proteinaceous cast formation and interstitial edema were demonstrated similar to previous studies in this nephropathy model $[20,21,24,30]$. We also found that serum BUN and Cr levels increased significantly in the CM group compared with the control group, supporting the nephrotoxicity of radiocontrast media to renal function. Pretreatment with PE extract demonstrated clearly its renoprotetctive effect by attenuating the severity of renal pathological damage and improving renal function with the dose dependent renoprotective effect of PE extract.

Oxidative stress has been proposed as one of the most important mechanisms in the pathogenesis of CI-AKI [31]. In vitro and in vivo studies demonstrate clearly that iodinated contrast media administration enhances hypoxia and increases the production of ROS within the kidney $[21,24,32]$. Lipid peroxidation is initiated as a result of the ROS induced abstraction of hydrogen in cellular membranes, which results in the formation of relatively stable compounds such as MDA. The production of free radicals is blocked by endogenous antioxidant systems such as TAC, SOD and CAT enzymes $[21,24]$. Thus, oxidative stress induced by contrast media during AKI is a relative excess of oxidants caused by increased free radical production and/or decreased antioxidant defense systems [20,21,24]. In the present study, increased MDA and decreased TAC, SOD and CAT enzyme activities in serum and renal tissues exposed to CM suggests that these enzymes were consumed due to increased oxidative stress. Decreased SOD and CAT scavenger activities results in higher $\mathrm{H}_{2} \mathrm{O}_{2}$ concentration and explains the change in the level of MDA during CI-AKI. The higher of antioxidant enzyme SOD and CAT activities and lower MDA in the PE extract pretreatment might be a response for renal injury after contrast administration. Thus, rats that receive PE extract before CM had decreased MDA and increased SOD and CAT activities in renal tissues could protected against CI-AKI from ROS. Moreover, the increased MDA and decreased TAC in rat plasma that exposed to $\mathrm{CM}$ reflect an increase in lipid peroxidation and decrease antioxidation in the systemic response. Thus, decreasing oxidative stress injury following PE extract application has been associated with antioxidant effects in circulation system.

Current recommendations to decrease the incidence of CI-AKI in high risk patients are hydration with saline, use of iso-osmolar contrast agents, minimum volume of contrast media, and avoiding nephrotoxic drugs [6,33]. Recent studies try to use antioxidants as protective remedies against CI-AKI have yielded conflicting results [34-36]. Antioxidant effect of PE was demonstrated in vitro and vivo studies by increased the concentration of antioxidant enzymes SOD and CAT and decreased MDA in lipid peroxidation [37-39]. The present study demonstrated that antioxidant effect of PE extract could decrease MDA in both plasma and renal tissues. Moreover, PE extract preserved plasma TAC and renal tissues TAC, SOD and CAT activities. These effects correlated with the attenuation of histopathological injury from contrast media administration. The dose dependent effect of PE extract started at dose $250 \mathrm{mg} / \mathrm{kg} / \mathrm{d}$ and had the additional effect at dose $500 \mathrm{mg} / \mathrm{kg} / \mathrm{d}$ similar to the antioxidant effect of vitamin $E$ in the experimental study 

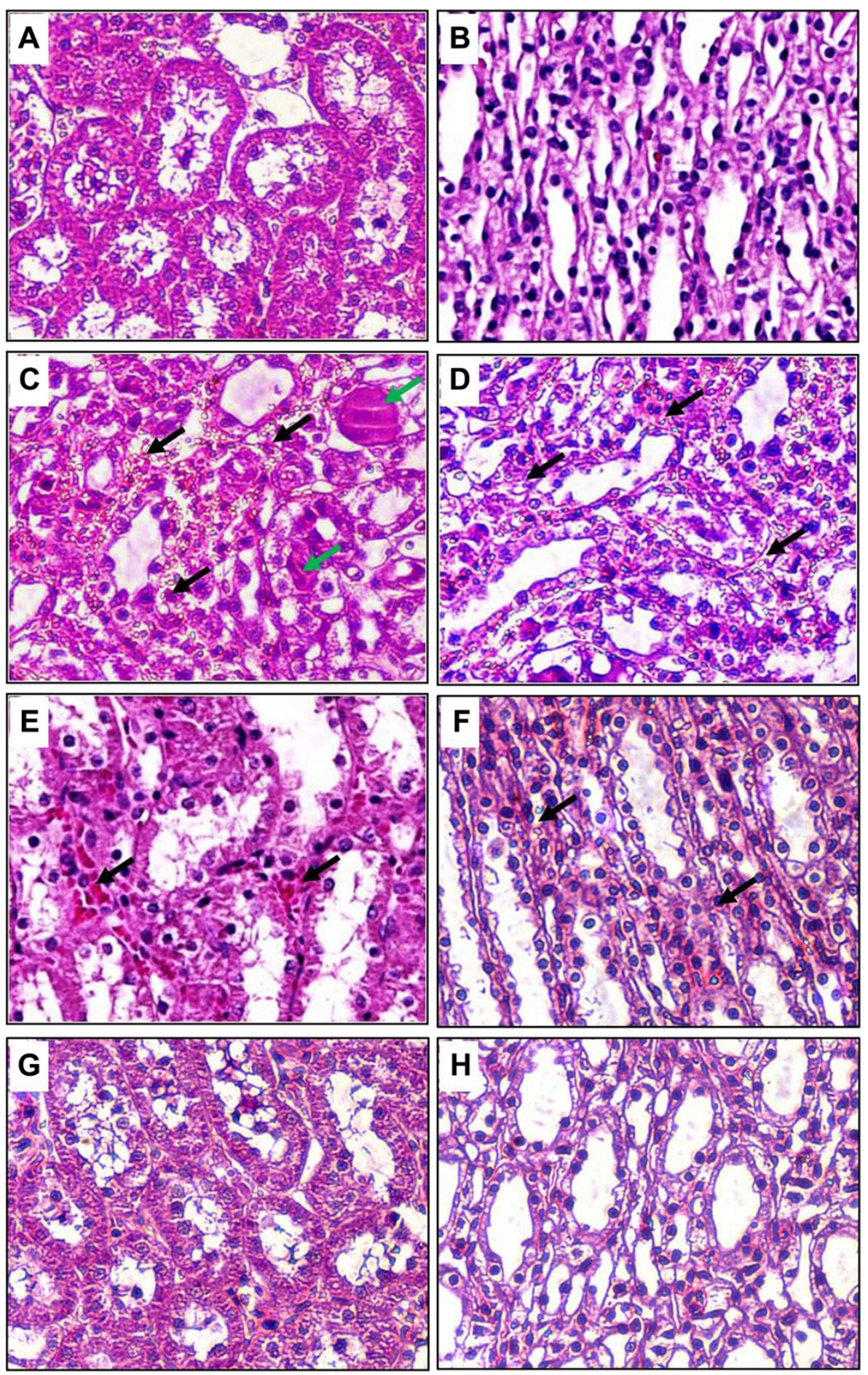

Figure $\mathbf{3}$ Histopathological with $\mathbf{H} \& \mathbf{E}$ staining of Cl-AKI in rats. A and $\mathbf{B}$ show normal rat kidneys in the cortex and medulla. Rats induced with CM (C and D) demonstrate severe TEC necrosis, moderate PTC congestion (black arrows) and proteinaceous casts (green arrows) in the cortex and medulla. Rats induced with CM and pre-treatment with PE extract $250 \mathrm{mg} / \mathrm{kg} /$ day (E and F) show a decrease in the severity of TEC necrosis, PTC congestion, and proteinaceous casts in the cortex and medulla. Interestingly, rats induced with CM and pre-treatment with PE extract $500 \mathrm{mg} / \mathrm{kg} /$ day (G and $\mathbf{H}$ ) demonstrate minimal TEC necrosis, PTC congestion or proteinaceous casts in the cortex and medulla, similar to control-rat kidneys. (Magnifications: $\times 400$ in A-H). CM: contrast media; PTC: peritubular capillaries; TEC: tubular epithelial cells. 


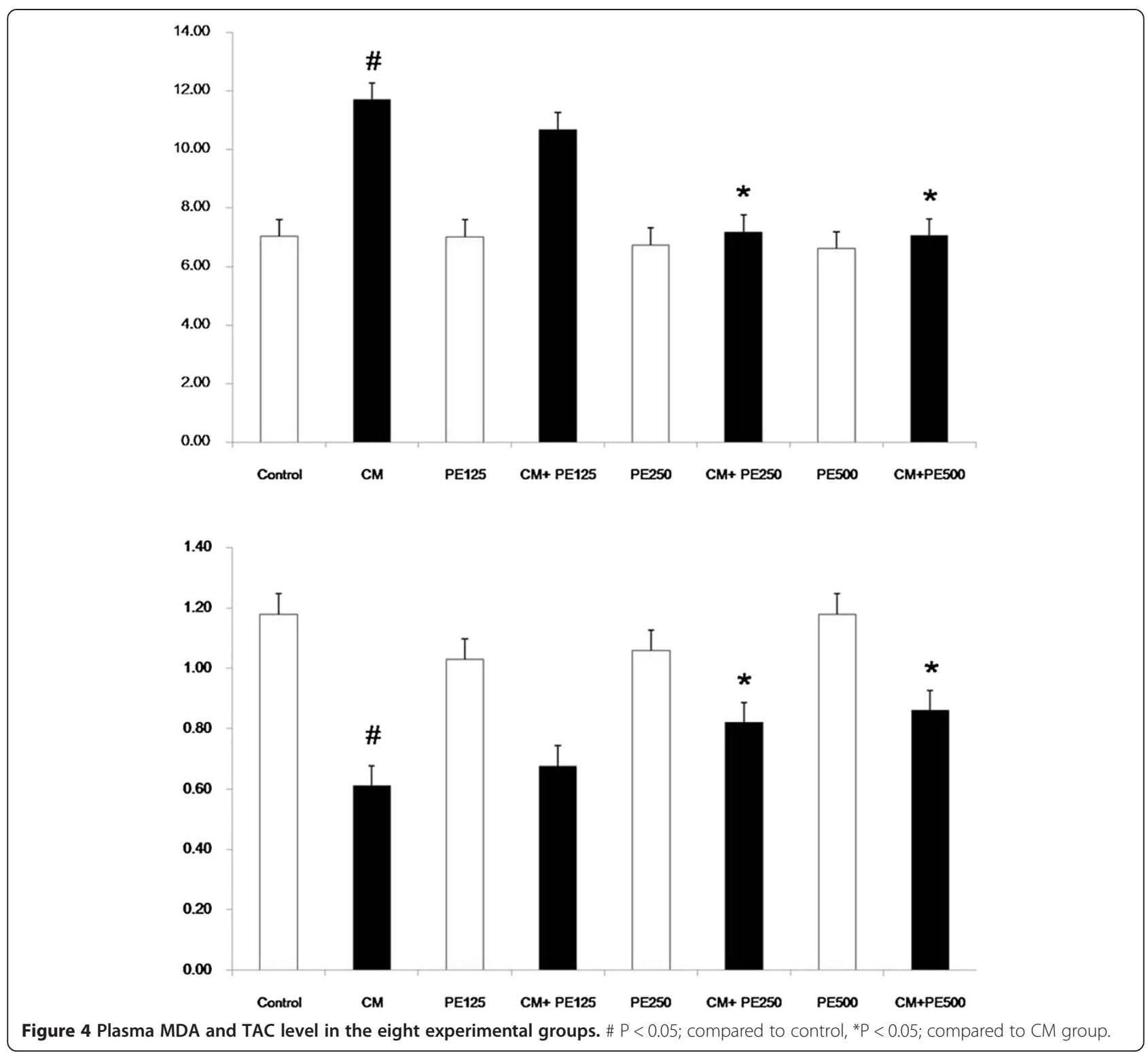

[21] and clinical trials $[25,40]$. Thus, the renoprotective effect of PE extract could prevent CI-AKI through antioxidant property.

Phyllanthus emblica is widely used in Thai traditional medicine and Ayurvedic Medicine for treatment of various diseases. The fruit of PE is known as a rich source of ascorbic acid [10,11], gallic acid [12], and also contains a mixture of phenolic compounds [13]. The major substrate which acts to be antioxidant in PE is gallic acid, vitamin $C$ and others depending on the technique that separates the compound from PE [41,42]. From the process to prepared PE extract in the present study, plant was dried by oven at $50^{\circ} \mathrm{C}$ before grinded and boiled in water. In general, vitamin $\mathrm{C}$ was destroyed by heat that could be loss from the preparing process [43]. In addition, PE extract by HPLC analysis in the present study showed the main substrate was gallic acid. Gallic acid is a polyphenolic compound with multiple hydroxyl groups which are able to donate its proton to break the chain reaction of free radicals consequently as a lipid peroxidation inhibitor [44,45]. Moreover, gallic acid was demonstrated as an excellent antioxidant with high free radical scavenging effect $[45,46]$. From the experimental studies, gallic acid was demonstrated to prevent or attenuate the severity of brain, heart and liver damage from ischemic or toxic substances injury [47-49]. Furthermore, the reno-protective effect of gallic acid from antioxidant and antiinflammation properties was demonstrated in many experimental studies in AKI against lindane [49], ferric nitriloacetic acid [50], and sodium fluoride [47] and chronic kidney disease [51]. By our HPLC analysis, gallic acid was present in $6 \%$ of the PE 

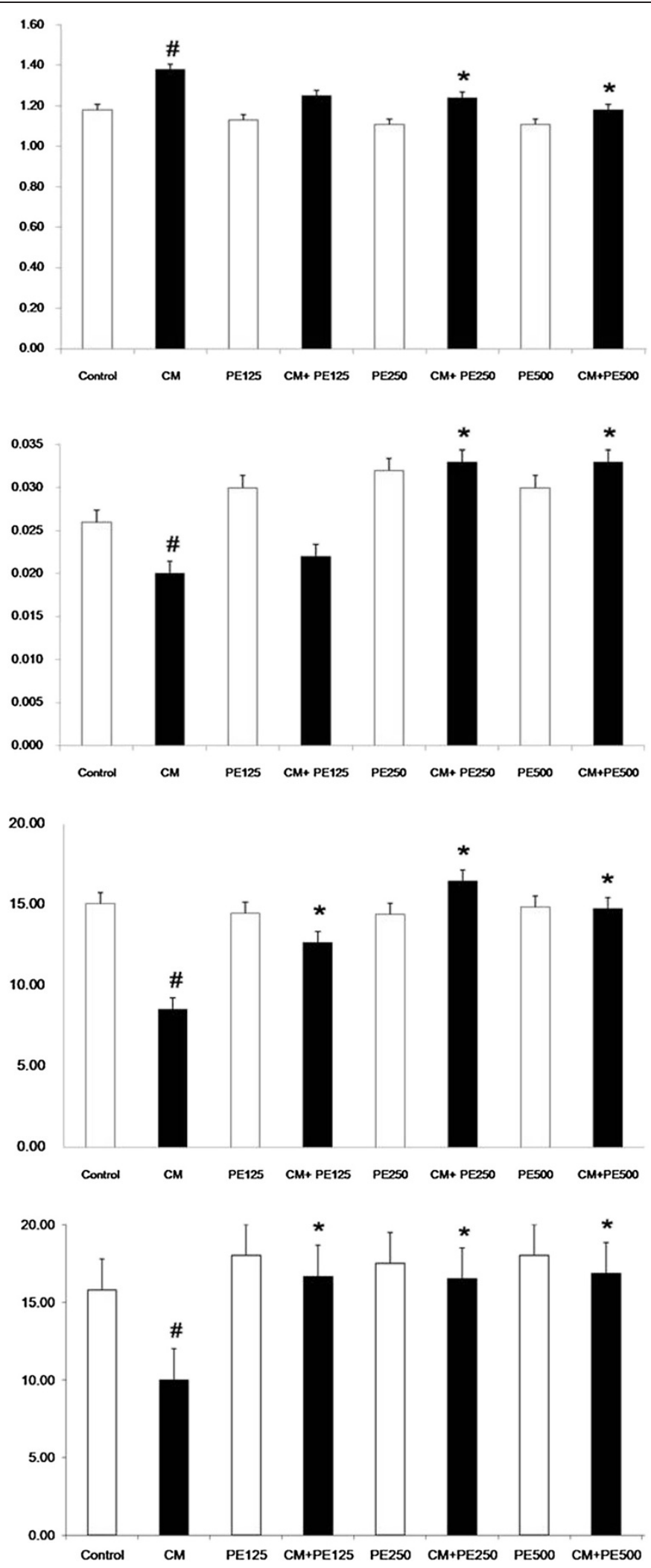

Figure 5 Renal tissue MDA, TAC, SOD and CAT level in the eight experimental groups. \# $\mathrm{P}<0.05$; compared to control, ${ }^{*} \mathrm{P}<0.05$; compared to CM group. 
extract, corresponding to doses of 15 and $30 \mathrm{mg} / \mathrm{kg} / \mathrm{d}$ in the 250 and $500 \mathrm{mg} / \mathrm{kg} / \mathrm{d}$ of PE extracts, respectively. These doses of gallic acid could be the basis of human studies. Thus PE extract administration could prevent CI-AKI in rats with antioxidant effect from gallic acid. These finding could be assessed in patients with high risk $\mathrm{CI}-\mathrm{AKI}$ in the future clinical trials.

The plasma levels of PE extract and the accumulation of PE extract on renal tissues with the repeated daily dose may be higher than the single dose administration. In experimental study, the bioavailability of gallic acid from grape seed polyphenol extract is improved by repeated dosing in rats [52]. The single dose with oral administration demonstrated that the intestinal absorption of gallic acid is poor $(<2 \%)$. While repeated exposure to the extract has shown the absorption of gallic acid was significantly higher than single dose treatment and reached to tissues level at day 10. Moreover, two gallic acid-derived compounds isolated from Casearia sylvestris leaves could reverse NK cell cytolysis which was suppressed from tumor growth when mice were treated with these compounds for 4 days [53]. In contrast, a single dose administration with a large volume and high concentration of any compound via oral route may cause adverse effects and could not reach to the therapeutic levels in the tissues. From these informations, we make the decision to give PE extract orally as presented in the protocol. However, a high dose administration of PE extract for 2 or 3 days before contrast administration should be evaluated for the preventing CI-AKI.

\section{Study limitations}

Monitoring of urine output and/or novel biomarker in plasma or urine is a much better indicator for early diagnosis of CI-AKI. However, we have measured only serum BUN and Cr levels. Also, we have only H\&E and PAS staining for histopathologic examination of renal tissues. Therefore, the immunohistochemistry staining such as Tunnel or PCNA and the evaluation of protein and gene expression in apoptosis or inflammatory pathway should be prepared to confirm CI-AKI.

\section{Conclusion}

The present study suggests that PE extract administration pretreatment for five days in dose 250 and $500 \mathrm{mg} /$ $\mathrm{kg} /$ day before the induction of CI-AKI exerts significant renoprotective effects in a rat model of CI-AKI. These finding indicate that PE extract could represent a novel and effective preventive approach for CI-AKI as a result of its antioxidant capacity to preserve renal function and directly protect renal tissues. Investigation with additional experimental studies and clinical trials is required to confirm to the advantage of PE extract to prevent the CI-AKI

\begin{abstract}
Abbreviations
Cl-AKI: Contrast-induced acute kidney injury; AKl: Acute kidney injury; CM: Contrast media; ROS: Reactive oxygen species; PE: Phyllanthus emblica; HPLC: High Performance Liquid Chromatography; MDA: Malondialdehyde; TAC: Total antioxidant capacity; SOD: Superoxide dismutase; CAT: Catalase; BUN: Blood urea nitrogen; AUC: Area under the curve.
\end{abstract}

\section{Competing interests}

All authors declare that they have no competing interest.

\section{Authors' contributions}

AT conceived the idea of study, designed the study protocol, collected the data, interpreted the data and wrote the manuscript. SK participated in the conceptualization of the design, carried out the technical aspect of the study, collected the data and revised the manuscript. Al prepared the samples, carried out the HPLC aspect of the study, collected the data and revised the manuscript. All authors read and approved the final manuscript.

\section{Acknowledgments}

This research was supported by operating grants from the National Research University Project of Thailand, Office of Higher Education Commission and Thammasat University

\section{Author details}

${ }^{1}$ Nephrology Unit, Department of Medicine, Faculty of Medicine, Thammasat University (Rangsit Campus), Klong Nung, Klong Luang, Pathumtani 12121, Thailand. 'Department of Preclinical Sciences, Faculty of Medicine,

Thammasat University (Rangsit Campus), Klong Nung, Klong Luang, Pathumtani 12121, Thailand. ${ }^{3}$ Division of Applied Thai Traditional Medicine, Faculty of Medicine, Thammasat University (Rangsit Campus), Klong Nung, Klong Luang, Pathumtani 12121, Thailand.

Received: 27 October 2013 Accepted: 15 April 2014

Published: 22 April 2014

\section{References}

1. Berns AS: Nephrotoxicity of contrast media. Kidney Int 1989, 36(4):730-740

2. Rudnick MR, Goldfarb S, Tumlin J: Contrast-induced nephropathy: is the picture any clearer? Clin J Am Soc Nephrol 2008, 3(1):261-262.

3. Gruberg L, Mintz GS, Mehran R, Gangas G, Lansky AJ, Kent KM, Pichard AD Satler $L F$, Leon MB: The prognostic implications of further renal function deterioration within $48 \mathrm{~h}$ of interventional coronary procedures in patients with pre-existent chronic renal insufficiency. J Am Coll Cardiol 2000, 36(5):1542-1548.

4. Brezis M, Rosen S: Hypoxia of the renal medulla-its implications for disease. N Engl J Med 1995, 332(10):647-655.

5. Tumlin J, Stacul F, Adam A, Becker CR, Davidson C, Lameire N, McCullough PA: Pathophysiology of contrast-induced nephropathy. Am J Cardiol 2006, 98(6A):14K-20K.

6. Mueller C, Buerkle G, Buettner HJ, Petersen J, Perruchoud AP, Eriksson U, Marsch S, Roskamm H: Prevention of contrast media-associated nephropathy: randomized comparison of 2 hydration regimens in 1620 patients undergoing coronary angioplasty. Arch Intern Med 2002, 162(3):329-336.

7. ACT Investigators: Acetylcysteine for prevention of renal outcomes in patients undergoing coronary and peripheral vascular angiography: main results from the randomized Acetylcysteine for Contrast-induced nephropathy Trial (ACT). Circulation 2011, 124(11):1250-1259.

8. Spargias K, Alexopoulos E, Kyrzopoulos S, lokovis P, Greenwood DC, Manginas A, Voudris V, Pavlides G, Buller CE, Kremastinos D, Cokkinos DV: Ascorbic acid prevents contrast-mediated nephropathy in patients with renal dysfunction undergoing coronary angiography or intervention. Circulation 2004, 110(18):2837-2842

9. Li Y, Liu Y, Fu L, Mei C, Dai B: Efficacy of short-term high-dose statin in preventing contrast-induced nephropathy: a meta-analysis of seven randomized controlled trials. PLOS One 2012, 7(4):e34450.

10. Tarwadi K, Agte V: Antioxidant and micronutrient potential of common fruits available in the Indian subcontinent. Int J Food Sci Nutr 2007, 58(5):341-349.

11. Krishnaveni M, Mirunalini S: Therapeutic potential of Phyllanthus emblica (amla): the ayurvedic wonder. J Basic Clin Physiol Pharmacol 2010, 21(1):93-105. 
12. Kumaran A, Karunakaran RJ: Nitric oxide radical scavenging active components from Phyllanthus emblica L. Plant Foods Hum Nutr 2006, 61(1):1-5.

13. Zhang YJ, Tanaka T, Iwamoto Y, Yang CR, Kouno I: Novel norsesquiterpenoids from the roots of Phyllanthus emblica. J Nat Prod 2000, 63(11):1507-1510.

14. Ngamkitidechakul C, Jaijoy K, Hansakul P, Soonthornchareonnon N, Sireeratawong S: Antitumour effects of Phyllanthus emblica L.: induction of cancer cell apoptosis and inhibition of in vivo tumour promotion and in vitro invasion of human cancer cells. Phytother Res 2010, 24(9):1405-1413.

15. Baliga MS, Dsouza JJ: Amla (Emblica officinalis Gaertn), a wonder berry in the treatment and prevention of cancer. Eur J Cancer Prev 2011, 20(3):225-239.

16. Singh I, Soyal D, Goyal PK: Emblica officinalis (Linn.) fruit extract provides protection against radiation-induced hematological and biochemical alterations in mice. J Environ Pathol Toxicol Oncol 2006, 25(4):643-654.

17. Ihantola-Vormisto A, Summanen J, Kankaanranta H, Vuorela H, Asmawi ZM Moilanen E: Anti-inflammatory activity of extracts from leaves of Phyllanthus emblica. Planta Med 1997, 63(6):518-524.

18. Bandyopadhyay SK, Pakrashi SC, Pakrashi A: The role of antioxidant activity of Phyllanthus emblica fruits on prevention from indomethacin induced gastric ulcer. J Ethnopharmacol 2000, 70(2):171-176.

19. Kusirisin W, Srichairatanakool S, Lerttrakarnnon P, Lailerd N, Suttajit M, Jaikang C, Chaiyasut C: Antioxidative activity, polyphenolic content and anti-glycation effect of some Thai medicinal plants traditionally used in diabetic patients. Med Chem 2009, 5(2):139-147.

20. Agmon Y, Peleg H, Greenfeld Z, Rosen S, Brezis M: Nitric oxide and prostanoids protect the renal outer medulla from radiocontrast toxicity in the rat. J Clin Invest 1994, 94(3):1069-1075.

21. Kongkham S, Sriwong S, Tasanarong A: Protective effect of alpha tocopherol on contrast-induced nephropathy in rats. Nefrologia 2013, 33(1):116-123.

22. Reichman J, Cohen S, Goldfarb M, Shina A, Rosen S, Brezis M, Karmeli F, Heyman SN: Renal effects of nabumetone, a COX-2 antagonist: impairment of function in isolated perfused rat kidneys contrasts with preserved renal function in vivo. Exp Nephrol 2001, 9(6):387-396.

23. Yamasowa H, Shimizu S, Inoue T, Takaoka M, Matsumura Y: Endothelial nitric oxide contributes to the renal protective effects of ischemic preconditioning. J Pharmacol Exp Ther 2005, 312(1):153-159.

24. Toprak O, Cirit M, Tanrisev M, Yazici C, Canoz O, Sipahioglu M, Uzum A, Ersoy R, Sozmen EY: Preventive effect of nebivolol on contrast-induced nephropathy in rats. Nephrol Dial Transplant 2008, 23(3):853-859.

25. Tasanarong A, Vohakiat A, Hutayanon P, Piyayotai D: New strategy of alpha- and gamma-tocopherol to prevent contrast-induced acute kidney injury in chronic kidney disease patients undergoing elective coronary procedures. Nephrol Dial Transplant 2013, 28(2):337-344.

26. Wong SH, Knight JA, Hopfer SM, Zaharia O, Leach CN Jr, Sunderman FW Jr: Lipoperoxides in plasma as measured by liquid-chromatographic separation of malondialdehyde-thiobarbituric acid adduct. Clin Chem 1987, 33(2 Pt 1):214-220.

27. Re R, Pellegrini N, Proteggente A, Pannala A, Yang M, Rice-Evans C: Antioxidant activity applying an improved ABTS radical cation decolorization assay. Free Radic Biol Med 1999, 26(9-10):1231-1237.

28. Aebi H: Catalase in vitro. Methods Enzymol 1984, 105:121-126.

29. Pisani A, Sabbatini M, Riccio E, Rossano R, Andreucci M, Capasso C, De Luca V, Carginale V, Bizzarri M, Borrelli A, Schiattarella A, Santangelo M, Mancini A: Effect of a recombinant manganese superoxide dismutase on prevention of contrast-induced acute kidney injury. Clin Exp Nephrol 2013, 17(3). Jun 27.

30. Wang YX, Jia YF, Chen KM, Morcos SK: Radiographic contrast media induced nephropathy: experimental observations and the protective effect of calcium channel blockers. Br J Radiol 2001, 74(888):1103-1108.

31. Detrenis S, Meschi M, Musini S, Savazzi G: Lights and shadows on the pathogenesis of contrast-induced nephropathy: state of the art. Nephrol Dial Transplant 2005, 20(8):1542-1550.

32. Zager RA, Johnson AC, Hanson SY: Radiographic contrast media-induced tubular injury: evaluation of oxidant stress and plasma membrane integrity. Kidney Int 2003, 64(1):128-139.

33. Aspelin P, Aubry P, Fransson SG, Strasser R, Willenbrock R, Berg KJ: Nephrotoxic effects in high-risk patients undergoing angiography. $N$ Engl J Med 2003, 348(6):491-499.
34. Jo SH, Koo BK, Park JS, Kang HJ, Kim YJ, Kim HL, Chae IH, Choi DJ, Sohn DW, Oh $\mathrm{BH}$, Park YB, Choi YS, Kim HS: N-acetylcysteine versus AScorbic acid for preventing contrast-Induced nephropathy in patients with renal insufficiency undergoing coronary angiography NASPI study-a prospective randomized controlled trial. Am Heart J 2009, 157(3):576-583.

35. Albabtain MA, Almasood A, Alshurafah H, Alamri H, Tamim H: Efficacy of ascorbic acid, $\mathrm{N}$-acetylcysteine, or combination of both on top of saline hydration versus saline hydration alone on prevention of contrastInduced nephropathy: a prospective randomized study. J Interv Cardiol 2013, 26(1):90-96.

36. Sun Z, Fu Q, Cao L, Jin W, Cheng L, Li Z: Intravenous N-acetylcysteine for prevention of contrast-induced nephropathy: a meta-analysis of randomized, controlled trials. PLoS One 2013, 8(1):e55124.

37. Sai Ram M, Neetu D, Yogesh B, Anju B, Dipti P, Pauline T, Sharma SK, Sarada SK, llavazhagan G, Kumar D, Selvamurthy W: Cyto-protective and immunomodulating properties of Amla (Emblica officinalis) on lymphocytes: an in-vitro study. J Ethnopharmacol 2002, 81(1):5-10.

38. Rajak S, Banerjee SK, Sood S, Dinda AK, Gupta YK, Gupta SK, Maulik SK: Emblica officinalis causes myocardial adaptation and protects against oxidative stress in ischemic-reperfusion injury in rats. Phytother Res 2004, 18(1):54-60.

39. Chen TS, Liou SY, Chang YL: Supplementation of Emblica officinalis (Amla) extract reduces oxidative stress in uremic patients. Am J Chin Med 2009, 37(1):19-25.

40. Tasanarong A, Piyayotai D, Thitiarchakul S: Protection of radiocontrast induced nephropathy by vitamin E (alpha tocopherol): a randomized controlled pilot study. J Med Assoc Thai 2009, 92(10):1273-1281.

41. Scartezzini P, Speroni E: Review on some plants of Indian traditional medicine with antioxidant activity. J Ethnopharmacol 2000, 71(1-2):23-43.

42. Habib Ur R, Yasin KA, Choudhary MA, Khaliq N, Atta Ur R, Choudhary MI, Malik S: Studies on the chemical constituents of Phyllanthus emblica. Nat Prod Res 2007, 21(9):775-781.

43. Reddy MB, Love M: The impact of food processing on the nutritional quality of vitamins and minerals. Adv Exp Med Biol 1999, 459:99-106.

44. Van Acker SA, Van den Berg DJ, Tromp MN, Griffioen DH, Van Bennekom WP, Van der Vijgh WJ, Bast A: Structural aspects of antioxidant activity of flavonoids. Free Radic Biol Med 1996, 20(3):331-342.

45. Lu Z, Nie G, Belton PS, Tang H, Zhao B: Structure-activity relationship analysis of antioxidant ability and neuroprotective effect of gallic acid derivatives. Neurochem Int 2006, 48(4):263-274.

46. Stupans I, Kirlich A, Tuck KL, Hayball PJ: Comparison of radical scavenging effect, inhibition of microsomal oxygen free radical generation, and serum lipoprotein oxidation of several natural antioxidants. J Agric Food Chem 2002, 50(8):2464-2469.

47. Nabavi SF, Habtemariam S, Jafari M, Sureda A, Nabavi SM: Protective role of gallic acid on sodium fluoride induced oxidative stress in rat brain. Bull Environ Contam Toxicol 2012, 89(1):73-77.

48. Stanely Mainzen Prince P, Priscilla H, Devika PT: Gallic acid prevents lysosomal damage in isoproterenol induced cardiotoxicity in Wistar rats. Eur J Pharmacol 2009, 615(1-3):139-143.

49. Vijaya Padma V, Sowmya P, Arun Felix T, Baskaran R, Poornima P: Protective effect of gallic acid against lindane induced toxicity in experimental rats. Food Chem Toxicol 2011, 49(4):991-998.

50. Prasad $L$, Khan $T H$, Jahangir $T$, Sultana $S$ : Effect of gallic acid on renal biochemical alterations in male Wistar rats induced by ferric nitriloacetic acid. Hum Exp Toxicol 2006, 25(9):523-529.

51. Peng CC, Hsieh CL, Wang HE, Chung JY, Chen KC, Peng RY: Ferulic acid is nephrodamaging while gallic acid is renal protective in long term treatment of chronic kidney disease. Clin Nutr 2012, 31(3):405-414.

52. Ferruzzi MG, Lobo JK, Janle EM, Cooper B, Simon JE, Wu QL, Welch C, Ho L, Weaver C, Pasinetti GM: Bioavailability of gallic acid and catechins from grape seed polyphenol extract is improved by repeated dosing in rats: implications for treatment in Alzheimer's disease. J Alzheimers Dis 2009, 18(1):113-124.

53. Da Silva SL, Chaar Jda S, Yano T: Chemotherapeutic potential of two gallic acid derivative compounds from leaves of Casearia sylvestris Sw (Flacourtiaceae). Eur J Pharmacol 2009, 608(1-3):76-83.

doi:10.1186/1472-6882-14-138

Cite this article as: Tasanarong et al:: Antioxidant effect of Phyllanthus emblica extract prevents contrast-induced acute kidney injury. BMC Complementary and Alternative Medicine 2014 14:138. 